\title{
O Poder Executivo no Estado Moderno
}

\author{
Themistocles Cavalcanti \\ Professor universitário e Ministro do Supremo \\ Tribunal Federal
}

Ao iniciar essa palestra ( $\left(^{*}\right)$ sobre o poder executivo no Estado Moderno desejo agradecer antes de tudo à V. Ex. ${ }^{a} \mathrm{Sr}$. Ministro do Interior pela honra do convite para participar dessa reunião. É uma honra e uma satisfação para mim poder assistir a esse simpósio e proferir a palestra inaugural. Desejo, ao, mesmo tempo, louvar a direção deste Ministério, principalmente, ao seu eminente Ministro porum a iniciativa que proporciona a quantos aqui trabalham, no setor jurídico, um amplo debate sobre temas que interessam aos diversos serviços deste Ministério. Săo extensivos esses louvores ao ilustre Consultor Jurídico do Ministério Dr. Luis Rafael Mayer pela forma exemplar com que organizou esse encontro.

$\mathrm{Na}$ verdade, depois que se valorizaram os estudos de outras profissóes, como, para exemplificar, a de econo-

(*) Autorizada pelo autor, a REVISTA DO SERVICO PÚBLICO divulga, neste artigo, textualmente, a conferéncia proferida pelo Ministro Themistocles Cavalcanti, na sessăo inaugural do Encontro Jurídico do Ministério do Interior, realizado em agosto de 1972, na Capital da República. mistas e administradores, os conselhos e a colaboração dos juristas têm sido quase postergados $e$, com grave injustiça, porque isto ocorreu justamente quando o direito começou a progredir no sentido de procurar os seus suportes nos fatos sociais e econômicos e melhor se relacionar principalmente com a economia, as ciências das finanças, as ciências administrativas, a ciência política, os fatores do progresso e desenvolvimento.

Năo há mais quem pense em aplicar o direito sem se apoiar na realidade $e$ nas ciências sociais e mesmo nas ciências exatas, criando novas disciplinas jurídicas como o direito nuclear, o direito espacial, o direito aeronáutico e tantos outros.

As disciplinas se multiplicam nesse setor como já se haviam multiplicado no campo económico e financeiro com o direito das sociedades, o direito fiscal e o direito agrário.

E que o direito sempre se apresenta como idéla de relação e tudo no mundo se traduz afinal em uma relação de 
pessoas, e de fatos. Mas sendo idéia de relação é também idéia de harmonia e de equilíbrio social, o que se obtém pelo princípio, ou pela norma, para atingir uma forma de convivência e de progresso social.

Qualquer que tenha sido o processo de elaboração, ele se conclui por um preceito ou uma decisão, que terá sempre uma expressão jurídica, pelo seu conteúdo e pela sua força obrigatória.

Por isso é que, mesmo quando elaborada por um leigo em direito, a mesma será formalmente uma norma jurídica, ainda que o seu conteúdo não reflita as condições substanciais do preceito Jurídico - mesmo quando não seja uma norma substancialmente justa ou substancialmente jurídica mas formalmente terá sempre uma expressão jurídica.

É preciso reconhecer e tenho dado provas dessa minha orientação, que o direito terá de se ajustar a exigências da realidade, que o direito há de evoluir com as novas condições de vida, mas também que há no direito um conteúdo ético que é essencial à validade da norma jurídica.

O número de teses apresentadas e a sua variedade dão bem idéia da perplexidade dos que trabalham nesta casa, no setor jurídico, diante de inúmeros problemas em que diariamente esbarram.

Esse interesse é um dado positivo e deve alertar aquilo que poderiamos chamar, não de indiferença oficial, mas de esquecimento de um setor importante de atividade funcional e diremos também cultural.
Esse esquecimento pode acarretar, a longo prazo, a marginalização de elementos úteis, por falta de aproveitamento, sendo difícil a recuperação de elementos humanos interessados e necessários para atender a setores importantes da vida pública.

Em tempos passados tem isto ocorrido, inclusive com a substituição da área jurídica, praticamente marginalizada, por pessoas com formação inteiramente imprópria para resolver problemas jurídicos.

E com intima alegria que assisto a essa iniciativa, na convicção de que o enfoque jurídico dos problemas não deve ser esquecido, mesmo quando não se aceite a solução proposta.

Quero neste momento, louvar a iniciativa, o seu valor humano, o estimulo que representa, aos que se encontram na área jurídica deste Ministério.

Mas, meus senhores, o meu tema é outro, e bem outro.

O tema que vamos abordar visa apenas oferecer uma larga visão sobre o poder executivo no Estado Moderno.

Seria iluscório pensar em penetrar profundamente no assunto. Desejo apenas definir a posição do poder executivo no Estado Moderno e algumas particularidades no exercicio das atribuições do Presidente da República.

Podemos, entretanto, desde logo advertir que só cuidaremos do poder executivo nos regimes democráticos, nos quais, apesar de todas as transformaçōes sofridas pelas estruturas politicas, domina, com maior ou menor amplitude, o principio da distribuiçăo de atribuições entre os poderes. 
Vale dizer que esse. pressuposto obedece a condições de ordem técnica, já que a crítica demonstrou que o princípio da chamada separação de poderes não tinha 0 sentido que erroneamente se lhes atribuia e que praticamente desarticulava qualquer sistema de Governo.

Pretendeu apenas Montesquieu estabelecer um regime de controle reciproco entre poderes para evitar um poder único e assim assegurar a liberdade. As críticas de Eisenmann, Carré de Malberg, de la Bigne de Villeneuve e tantos outros, deram uma interpretação ao sistema de Montesquieu que nem um pouco the tirou o brilho da sua construção, mas afastou uma interpretação negativa do funcionamento dos poderes.

A verdade é que, como veremos, as relações entre poderes ainda constitui, na prática, a grande dificuldade ao crescimento desmedido de qualquer dos poderes.

Outra discriminação importante a ser feita seria a dos regimes presidenciais e parlamentares.

Mas, estudo comparado seria difícil se tivéssemos de analisar o crescimento do executivo em termos de poder e do exercício do poder em cada um dos regimes.

O parlamentarismo alemão e o francês são, entretanto, exemplos daquilo que $\circ$ executivo pode exercer como poder no regime parlamentar. A institucionalização do regime favorece esse fortalecimento.

Mas o que nos interessa precipuamente é a evolução sofrida pelo executivo nos tempos modernos, pelos seus novos métodos de ação, a multiplicação dos seus recursos, seguindo a própria transformação da sociedade de que ele participa.

Finalmente, seria de examinar um novo sistema de relações entre o executivo e o legislativo, como veremos.

Dentro desse esquema é que se desenvolveu 0 executivo.

o fortalecimento, ou para melhor dizer, a expansão dos poderes do executivo não foi sempre, como parece a muitos, determinada pela necessidade de aumentar o seu poder e eventualmente absorver outros poderes como nos regimes totalitários.

Essa expansão se realiza, normalmente, como contingência de uma transformação social e de um crescimento da área necessária de ação do executivo, assoberbado por novas responsabilidades.

O crescimento populacional, o aumento do comércio internacional, a agravação dos problemas urbanos, o progresso tecnológico, o surgimento de uma sociedade de massas e tantas e tantas outras causas são determinantes necessárias do aumento do poderio do executivo, pela ampliação de sua equipe de trabalho e da organização dos seus serviços administrativos.

A renovação começou nos Estados Unidos, mais intensamente na Presidência Roosevelt, na base do relatório feito para a Presidência, no qual são tratados desde os mais graves problemas administrativos, até a mecânica do "decision making process" e do exercício do poder normativo pelo executivo, dois instrumentos do seu fortalecimento. 
Participaram desses estudos as maiores sumidades naquela época, nomes até hoje conhecidos como Luther Gulick, Louis Brownslow, Cushman, Emmerick, James Hart e tantos outros.

Cuidaram esses estudos principalmente:

$1 .^{\circ}$ - do problema do pessoal;

2. ${ }^{\circ}$ - do sistema de controle financeiro;

3.0 - das "commissions" destinadas ao controle das "public utilities";

4. ${ }^{\circ}$ - dos problemas departamentais e das áreas de serviço federal;

5. - das corporações g o vernamentais;

6. - do poder normativo ( $\mathrm{rule}$ making);

7..$^{\circ}$ - do preparo das medidas a serem propostas ao Parlamento pelos departamentos administrativos.

Basta este quadro para mostrar como se desenvolveram os trabalhos destinados a dar novo estímulo ao poder executivo para alargar a sua área de ação e dar expansão às necessidades crescentes do poder executivo.

Mais tarde, em 1949, depois da guerra, o famoso e volumoso relatório Hoover, procurou dar ainda melhor estrutura ao poder executivo.

Já em 1939 o "Reorganization Act" havia dotado o poder executivo de nova estrutura que, com o correr dos anos, foi melhorando, e que se constituira hoje, salvo erro, dos-seguintes órgãos:
1 - do pessoal da Casa Branca;

2 - da secretaria do Gabinete;

3 - do Bureau do orçamento;

4 - do Conselho de consultores econômicos (council of economic advisers) criado em 1946 pelo National Security Act.

5 - do Conselho de Segurança Nacional (National Security Council) criado em 1947;

6 - da Agência Central de Inteligência;

7 - da Agência de Mobilização da Defesa Civil;

8 - da Civil Service Commission.

Estes dados, certamente incompletos, justificam a afirmação da transformação completa do executivo.

\section{Ainda mais:}

Os Conselhos, as Comissões, as Assessorias, aquilo que Wheare chamou de Governo por Comissões é apenas uma parte desta vasta máquina que é o executivo, desdobrada por um sistema de administração indireta que inclui corporaçōes, agências especializadas, empresas públicas, vinculações as mais intimas com a grande empresa privada, com os centros de pesquisas e universidades que participam das atividades públicas com os seus conhecimentos tecnológicos.

Poucos imaginam o que representam na vida econômica e política de um pais, por exemplo, como os Estados Unidos, as Comissões de Energia Nuclear e de Vôos Espaciais. 
Den Price em seu excelente livro sobre o Governo e a Ciênca mostra com abundância de detalhes 0 poder das Comissões e Assessorias ao penetrarem nos setores mais importantes da politica interna e externa.

E por isso que os críticos do sistema constitucional americano têm focalizado os poderes do Presidente, dando ênfase às transformações sofridas no decurso da evolução da vida americana.

Vejamos, ao acaso, o que diz Bernard Schwartz, um dos mais conceituados:

"A estrutura do Governo criada pelo texto da Constituição adotada nos fins do século XVIII, está, todavia, inteiramenta diferente daquela que existe na maioria das do século vinte. $O$ equilibro entre os Estados e a Nação sobre o qual se baseou 0 sistema federal e dele depende, foi substancialmente alterado. A autoridade do Governo Central aumentou constantemente, às custas dos poderes dos Governos dos Estados.

A intervenção de Washington em matéria que era considerada de competência puramente local tem se tornado tão freqüente que é licito indagar se os Estados não se tornarão meros vestígios de um sobrevivente, de um velho e florescente sistema federal.

Também no Governo Nacional o equilibrio entre os poderes foi perturbado. O poder do executivo americano foi crescendo às expensas do legislativo e judiciário. Essa mudança no centro de gravidade constitucional nos Estados Unidos alterou drasticamente a separação de poderes, sobre o qual nasceu a Constituição Americana. Fez do Gabinete do Presidente o mais poderoso posto eletivo do mundo. O Presidente dos Estados Unidos possui hoje mais autoridade que poderia ter sido possivel admitir para a maioria dos Anglo-Americanos contemporâneos de George III".

\section{(American Const. Law - pág. 5).}

$E$ isso não é novidade para ninguém.

Vamos, entretanto, prosseguir com mais uma amostra de poder executivo modernizado.

Na França, a Quinta República procurou restaurar a força do executivo, ou em outras palavras, restaurar o poder governamental, na palavra dos críticos do regime.

Esse objetivo foi, antes de tudo, político, e procurou ser atingido pela participação maior do Governa no processo legislativo, a começar pela iniciativa legislativa.

Hoje é o Governo afinal quem aqui conduz o processo legislativo em uma Câmara livre para votar, às vezes dentro de certos prazos.

Não poderia ser de outra maneira quando a Constituição diz que é o Governo quem determina e conduz a politica da Nação.

Por isso foi preciso, na opinião dos críticos mais autorizados da Quinta República, restabelecer a posição do Governo na área legislativa, reduzir o conceito de lei, ampliar o de "ordonnances". 
Técnica e politicamente o Governo fortaleceu-se.

Administrativamente a sua solidez sempre foi grande. A administração francesa está estruturada de tal forma, possui quadros tão perfeitos, que nenhuma crise política conseguiu até hoje abalar os seus alicerces, nem mesmo as piores crises parlamentares da Terceira e Quarta Repúblicas.

Foi uma estrutura, entretanto, que progrediu sabiamente. Assimilou todos os modernos processos da administração científica, nacionalizou numerosos serviços públicos essenciais, bastando citar os trens e a eletricidade, criou numerosas empresas públicas, de origem tradicionalmente francesas e cresceu de forma a atender a todas as necessidades de um bom serviço público.

O Presidente, por outro lado, dispõe de instrumentos que permitem realizar os objetivos de uma política e administrativa modernas.

O nosso poder executivo seguiu, dentro de outra técnica constitucional, o modelo americano.

Executivo forte, poder pessoal do Presidente, comando das Forças Armadas e da Política Exterior, Comando do Comércio Exterior e da Segurança Nacional.

Já o havia visto Haroldo Laski:

"O campo das funções é vastíssimo. O Presidente é o chefe do Cerimonial do Estado. E uma fonte vital de propostas legislativas. E a fonte ûl- tima de qualquer decisão do Executivo. É o máximo expoente da política externa da Nação. Somar todas essas funções à continua necessidade de ser, ao mesmo tempo, o homem representativo da Nação, e o chefe do seu Partido Político significa, à evidência, apelar para as energias de um só homem de maneira não superada por nenhum outro cargo político no mundo".

Guardadas as devidas proporções é - Presidente em qualquer Presidencialismo. Já o está querendo ver, em alguns parlamentarismos...

Graças ao sistema democrático, porém, foi possível evitar a maioria dos excessos e construir um executivo forte mas limitado em seus poderes pela própria lei. O Presidente é forte apenas pelos seus poderes constitucionais.

Não vou fazer o histórico desse sistema entre nós, apenas dizer que adotamos o executivo americano e, como ele, crescemos por contingência do progresso na vida do Estado.

O Presidente da República exerce atribuiçőes, antes de tudo, politicas, porque o poder político sobreleva todos os demais.

O Chefe do Executivo é o Chefe do Estado, o Chefe Supremo das Forças Armadas, o condutor da política exterior, o defensor maior do interesse público, o Presidente do Conselho de Segurança Nacional.

Ele atua assim em uma larga área onde age livremente, dirigindo a poli- 
tica interna, orientando a política internacional e escolhendo os seus meios de ação.

Deve o Presidente exercer, assim, uma liderança porque, com os seus poderes e a soma dos interesses que representa, ele não se pode alhear das direções partidárias e das suas relações com os líderes políticos

Neste ponto, deve se aproximar necessariamente do Congresso. Woodrow Wilson chamaria o regime de "Congressional Government", porque na verdade, o Presidente não se pode desinteressar da vida partidária que tem a sua expressão no Congreso.

A observação de Wilson denuncia uma falha do Presidencialismo que merecia correção pelo perigo de transferência do poder ao Congresso com a multiplicação dos Partidos.

Sob a Constituição de 1946, com numerosos partidos, já se verificara muitas vezes que os negócios do Governo, com tantos partidos, eram feitos a custos elevados.

Não é este, porém, o espírito do regime presidencialista.

Desde 1967, entretanto, a posição. do Presidente veio se alterar profundamente com as seguintes medidas:

a) ampliação do direito de iniciativa das leis;

b) andamento especial de certos projetos de lei de iniciativa do executivo;

c) delegação legislativa; d) faculdade concedida ao Presidente da República para expedir decretos-leis em certas matérias;

e) competência do Presidente da República para decretar o estado de sítio ou a intervenção nos Estados - ad referendum do Congresso.

Mas seria insensato separa $\circ$ Presidente do Congresso ou o Executivo do Legislativo, porque o Governo Constitucional não vive sem o Congresso. Dai dizer Pritchelt - que algumas das funções mais importantes do Presidente são as legislativas.

Em matéria administrativa o crescimento foi imenso e tomaria tempo para avaliar as proporções da expansão dos serviços a cargo do executivo nesses últimos anos.

O Decreto-lei $n .^{\circ} 200$ dá bem uma idéia do que representa hoje o quadro da administração federal através da administração direta e indireta.

Mas não desejo sair da generalidade dos problemas centrais da politica do Governo, para não me perder em uma análise da qual não poderia sair no tempo limitado de que disponho.

O sistema presidencial foi instituido em momento grave da história americana e o mesmo ocorreu entre nós. Mas não previram os seus fundadores, nem de longe, as dificuldades que teriam de enfrentar.

Não obstante, o regime foi instituído para ter um Presidente forte, o que quer dizer, um executivo forte. 
Já dizia Hamilton no Federalista (n. ${ }^{\circ}$ LXX):

"Um Executivo fraco supõe governo fraco. Ora, execução fraca não é outra cousa senão má execução e um governo que executa mal, só pode ser um mau governo".

Mais adiante:

"O que dá força a um governo é, antes de tudo, a sua unidade, em segundo lugar, a sua duração, ter- ceiro a sua possibilidade de prover as próprias necessidades e quarto estar investido de poderes suficientes para governar.

O que dá segurança ao governo é não só uma dependência razoável do povo, mas também uma responsabilidade ponderável".

E Justifica Hamilton as suas palavras à luz dos precedentes e dos ensinamentos da história.

Este Presidente, entretanto, deveria para se legitimar ser constitucionalmente forte, isto é, investido de poderes constitucionais que the atribuem força e poder, dentro do mecanismo de um sistema legal.

Pressupõe o exercicio do poder dentro de suas atribuições constitucionais.

Há, entretanto, sutilezas a verificar na verdadeira função do Presidente como chefe politico e constitucional, cujo poder pressupõe também apoio popular e um certo lastro político obtido através do Congresso.

Por isso que é do maior relevo apurar, em qualquer regime constitu- cional, como se processam as relações entre Governo e Congresso.

Já se disse que a Quinta República Francesa tem, como pedra de toque, estabelecer relações mais intimas entre - Parlamento e um Governo forte, o que se efetuou realmente por meio de uma nova concepção do processo legislativo, um novo conceito de lei e o aumento da iniciativa do executivo no processo de elaboração da lei.

$\mathrm{Na}$ prática política a solução não deixa de ser racional porque, dessa intimidade, podem nascer bons resultados, entre os quais o menor não será, certamente, o enriquecimento da informação legislativa.

Lá como aqui, onde o processo também foi utilizado, não deixou de criar suscetibilidades.

O legislativo sentiu-se arranhado, diminuído, quase que espoliado, mas esta é uma reação superficial, epidérmica, porque, na realidade, pelo me. quando a participação do executivo na elaboraç̧ão legislativa é sistema antigo.

Já Carré de Malberg mostrava como ela existia com o exercício do veto.

Já observava Oswaldo Trigueiro referindo-se à Constituição de 1946:

"Em matéria propriamente legislativa a iniciativa do Presidente prevalece sempre sobre a vontade do Congresso, quando esta é manifestada por maioria simples. Verifica-se, portanto, acrescenta que a participação do Presidente no processo legislativo é substancial. Ele não só 
tem atribuições de natureza legislativa - como é de um certo modo, um dos órgãos do Poder Legislativo. Há quem o compare a uma terceira Câmara. Os Poderes do Presidente são nesse particular mais amplos dos que os conferidos pela Constituição e pelos costumes ao Presidente dos Estados Unidos.

Em primeiro lugar, porque o nosso goza de um poder de iniciativa, parcialmente exclusivo, que o direito americano conhece..."

O que se fez em 1967 e 1969 em relação à função legislativa foi apenas rever velhas fórmulas, modernizálas, torná-las mais eficazes.

Croskey faz sobre este assunto interessantes ponderaçöes, relembrando conceitos de Blakstone sobre as limitações do legislativo. Relembrava então que o antigo Congresso do tempo dos Artigos de Confederação teria os seus poderes divididos entre os executivo e judiciário.

Daí a enumeração dos poderes do Congresso.

Não me refiro, é evidente, a outras restrições sobre as pessoas dos parlamentares, quando as reações se justificam, pelo menos quando não se examinam as causas transitórias dessas restrições, mas sobre o processo legislativo.

O que se procurou foi apenas modernizar, voltando-se às origens do regime dos parlamentares, notadamente - Britânico, a mais velha das instituições parlamentares, onde se encon- tram preceitos perfeitamente atuais como os que se seguem, como exemplo.

Inscritos no Act of Parliament:

a) O parlamento não pode votar em matéria financeira sob qualquer pretexto, a não ser a pedido dos Ministros da Coroa;

b) o parlamento só pode criar impostos por iniciativa da Coroa, o mesmo acontecendo para 0 aumento de qualquer tributo.

De lá para cá os Parlamentos do mundo inteiro passaram por numerosas reformas, para melhor ou para pior, mas agora procuram se ajustar ao mecanismo do Governo.

É que o problema de prestígio da existência das Câmaras está ligado ao da eficácia dos seus trabalhos.

Mas esta eficácia depende da existência de instrumentos de trabalho. $E$ o executivo está em condição de fornecê-los.

Sob o ponto de vista teórico nada impede essa participação do executivo. Há muito que a crítica reduziu o principio da separaçăo dos poderes às suas justas proporçōes.

Como Já disse Montesquieu, numa pretendeu separar os poderes mas apenas garantir a liberdade, evitando a sua confusão em um só e procurando um sistema de equilibrio entre os poderes.

O que Easton, Bergeron e outros pretendem é fundar uma doutrina ba- 
seada não na separação de poderes, mas na discriminação de função.

Observa com razão o professor André Hauriou que no quadro do Estado moderno é principalmente o Governo que deve informar o Parlamento. Antigamente, quando os problemas politicos eram relativamente simples e que o Estado, só penetrava no terreno econômico com grande discrição, os notáveis de cada circunscrição podiam ter bons conhecimentos dos negócios e problemas políticos do Estado. Hoje a técnica se mistura com a política de modo complicado e o poder político é divorciado dos técni$\cos$, o que dificulta, de muito, a formação de um juizo exato desses problemas pelos políticos.

E conclui com ironia. É por isso que faz alguns anos, a parlamentar, privado das melhores informações, se vê um pouco, em face do governo, na situação de um amador, diante de uma equipe de profissionais.

Há evidente exagero na observação do eminente mestre de Paris, mas o certo é que o politico tem hoje aqui, como em toda a parte, pois o depoimento citado não foi nosso, uma visão insuficiente dos problemas pela escassez de dados e informações que podem manipular. (Droit Const., pág. 726).

Como estudioso do direito constitucional não estaria longe de admitir a revisão dos textos constitucionais sobre "Comissões Parlamentares de inquérito" $\theta$ sobre "pedidos de informação", no sentido de favorecer a investigação legítima sobre matéria que in- teressa a atividade legislativa, mas sempre disciplinada em preceito constitucional, que evite os excessos.

A colaboração - governo-legislativo - deve ser feita através de Câmaras tanto quanto possivel, bem informadas.

O que faltaria talvez às Câmaras é a existência de órgãos competentes para colher, reunir e divulgar informações obtidas sistematicamente dos órgãos executivos.

Esta é a perspectiva que temios das relações Governo-Congresso.

São essas as principais considerações gerais que o tema merece.

Não quero, entretanto, concluir esta exposição sem abordar dois problemas constitucionais surgidos no texto da Emenda $n .^{\circ} 1$, mas, segundo me parece, de importância.

O primeiro se refere à competência do Presidente da República para estruturar as repartições, regular o seu funcionamento e fixar atribuições, através de ato executivo.

O segundo será sobre a delegação de poderes, preceito que vem de 1967 e foi reformulado em 1969.

\section{Vamos apreciá-los rapidamente.}

O problema da organização do poder executivo oferece objetos extremamente importantes.

Um deles é a organização de uma estrutura administrativa própria, com 
elementos humanos e materiais necessários à realização dos objetivos governamentais.

Foi o que se chamou nos Estados Unidos de "institucionalização do executivo", e que nada mais é senão a criação em torno do Presidente dos órgãos que possam auxiliá-lo a desincumbir-se dos pesados encargos.

Essas forças precisam ser conjugadas sob um comando único, mas obedecendo também a uma unidade de conceito que permitam a boa compreensão entre o chefe e os seus assessores em todos os graus.

Tudo isso exige uma orientação administrativa que obedeça a um planejamento tecnicamente certo e politicamente orientado pelo chefe.

O que ocorre nos Estados Unidos também está acontecendo na Alemanha, na França e outros países não totalitários.

Esse esforço de racionalização e esta preferência pelas soluções técnicas, sofre, entretanto, as inevitáveis restrições dos setores políticos que pretendem muitas vezes fazer prevalecer as soluções preconizadas pelas lideranças políticas.

Cabe ao Presidente da República, afinal, ser o árbitro na opção da meIhor solução em cada caso.

É preciso, entretanto, reconhecer que o velho conceito de que a solução técnica deveria estar em baixo da política (on the tap but not on the top) já está sendo revista pela conveniência de atribuir a necessária importância às soluçōes técnicas, pelo aproveitamento do progresso tecnológico que já nos produziu a revolução industrial. Apesar de tudo a influência política na decisão é inevitável - Política, já se vê, no grande sentido.

Tecnicamente o mecanismo legislativo já se adaptou a essas contingências, por meio do processo de delegação legislativa que concilia o preparo e elaboração das resoluções, para submetê-las, afinal, ao beneplácito político do poder político.

Entre as atribuições do Presidente da República há uma que constitui novidade em nosso direito e que exigiria uma atenção especial pelo que representa no exercício do poder normativo pelo Presidente da República.

Queremos nos referir especialmente ao que dispõe o inciso $V$ do artigo 81 da Constituição, quando atribui ao Presidente da República competência para:

"dispor sobre a estruturação, atribuições e funcionamento dos órgãos da administração federal".

Vejamos o sentido desse dispositivo novo e de grande importância na definição da competência do Presidente da República.

A idéia de incluir esse preceito na Constituição veio da Comissão de Alto Nivel nomeada pelo saudoso Presidente Costa e Silva para redigir a atual Emenda n. ${ }^{\circ} 1$.

A idéia foi bem aceita porque não representava nenhuma invasão da área 
legislativa, mas liberava o poder executivo de dificuldades existentes para a reestruturação dos órgãos da administração, redistribuição de funções e medidas destinadas a facilitar o seu funcionamento.

Nos Estados Unidos há muito que essa área é aberta ao executivo e na França a Quinta República definindo melhor os limites da lei, deixou larga margem às funções do poder executivo no terreno administrativo.

Analisando bem o texto verificamos que ele se refere, em relação aos órgãos da administração, a três cousas:
a) estruturação;
b) atribuição;
c) funcionamento.

Verificando a competência do poder legislativo nada se encontra relativamente à organização da administração pública federal, a não ser criação de cargos e fixação de vencimentos além de toda a matéria de competência da União.

Deve-se aqui remeter ao art. $8 .^{\circ}$ onde se encontram na realidade alguns serviços que exigem lei federal (Telecomunicações, energia elétrica, navegação aérea, certas vias de transportes), bem como matéria legislativa geral sobre orçamento, gestão patrimonial e financeira, etc.

Não me parece, entretanto, que o preceito constitucional seja tão ambicioso que atinja situações jurídicas só alteráveis por lei. Nem sequer por decreto-lei esses problemas administra- tivos podem ser resolvidos (art. 55 da Constituição) - (segurança nacional, finanças públicas, criação de cargos e fixação de vencimentos).

O que se visou com o preceito foi: fazer modificações por decreto executivo, dando nova estrutura ao órgão, novas atribuiçōes a seus funcionários e dispor sobre o seu funcionamento, sem alterar o status juridico dos seus funcionários.

É evidente que outorgadas, pela Constituição, essas alterações podem ser feitas com uma mobilidade maior na organização administrativa, na possibilidade de mudanças na administra. ção dos serviços e seus departamentos, etc.

Não é mais necessária uma lei para o ordenamento do regime das repartições. A modificação por meio de decreto dá maior mobilidade às estruturas administrativas e permite a sua dinamização. Não deve, entretanto, o executivo exceder-se no exercício dessas atribuições que sofrem limitações gerais pela competência legislativa das Câmaras.

Mas isto só pode ocorrer quando ferir situações jurídicas definitivas.

Essa prerrogativa do Presidente da República, envolvendo uma boa faixa do poder normativo, é da maior importância para a eficiência da administração pública mas, poucas vezes, tem sido a sua importância posta em relevo.

$\mathrm{Na}$ realidade, o poder normativo exercido por meio de decretos executivos concorrem, até um certo ponto, 
com a função legislativa, salvo naquilo que diz com as conseqüências jurídicas que decorrem das alterações na estrutura e nas atribuições dos órgãos da administração pública, direta ou indireta.

Somente a aplicação do preceito, entretanto, permitiria um Julgamento definitivo sobre o exercício dessa competência em cada caso.

Outra questão importante é aquela que se refere à competência dada ao Presidente da República para autorizar a delegação aos Ministros de Estado (Art. 33), nos seguintes casos:

1 - no provimento dos cargos públicos federais na forma da Constituição e das leis;

2 - na autorização a brasileiro para aceitar função, emprego ou comissão de Governo estrangeiro;

3 - no conceder indultos, comutar penas com audiência se necessário, dos órgãos insțituidos em lei;

4 - no dispor sobre a estruturação, atribuição e funcionamento dos órgãos de administração federal.

Basta formular a quesião para verificar da sua importância e da sua gravidade, pela natureza da matéria compreendida nessa faculdade de delegar.

Mas em que consiste a delegação?

Embora admitida como prática antiga, entre nós, ela não tem passado de mera autorização para a prática de atos de rotina adminisrativa.

A Lei n. ${ }^{\circ} 200$ foi mais precisa e procurou conceituar e ampliar a delegação no seguinte preceito do seu artigo 11:

"É facultado ao Presidente da República - aos Ministros de Estado e em geral às autoridades da Administração Federal - , delegar competência para a prática de atos admitrativos, conforme se dispuser em regulamento.

Parágrafo Único - $\mathrm{O}$ ato da delegação indicará com precisão a autotoridade delegante, a autoridade delegada $e$ as atribuições objeto da delegação".

O que me parece é que a delegação da Lei n.० 200 se refere à delegação de atribuições.

Em todo o caso, o texto é tímido como o era o do art. 83 , parágrafo único da Constituição de 1967.

Vale a pena recordar o que existe na doutrina. Laubadère, por exemplo, distingue a delegação de simples assinatura da delegação de funções.

Pela primeira o que se autoriza é apenas a assinatura do expediente. A autoridade delegante conserva-se no seu cargo e continua a orientar o trabalho, apenas o expediente, o trabalho material do expediente é desempenhado por outrem. Nas delegaçōes de funções, as razões de decidir pértencem a quem pratica o ato, é ela quem conhece os fundamentos do seu ato. 
Deve, entretanto, satisfazer algumas exigências:

a) quanto ao ato da delegação $e$ sua forma;

b) ao ato que autoriza a delegação;

c) a maneira pela qual é executada a função delegada.

A inobservância de qualquer exigência pode invalidar 0 ato.

A Emenda n. ${ }^{\circ} 1$ - facilitou a outorga de delegação porque suprimiu a exigência de lel para autorizar a delegação - Hoje o Presidente da República pode outorgar a delegação sem autorização legislativa.

O que existe em nosso direito e tem a abonar a tese, decisão unânime do Supremo Tribunal Federal (M.S. 18.558, de 14 de junho de 1968 - R.T.J. 46 - pág. 748) que considera constitucional a delegação do Presidente da República ao Ministro de Estado, que passa a assumir responsabilidade integral pelo ato que praticou por delegação.

Como, porém, considerar o preceito do Decreto-lei n. ${ }^{\circ} 200 \mathrm{em}$ face da Emenda $\mathrm{n} .{ }^{\circ} 1$ ?

Em primeiro lugar, quando ele se refere ao Presidente da República há de se excluir os casos em que a competência do Presidente é constitucional e, por isso mesmo, não pode ser delegada a não ser nos casos dos itens V - VIII - XVIII - XXII.

Em segundo lugar, a autorização para delegar não depende mais de regulamento, isto é, de ato do Presidente da República de natureza normativa, onde se devem estabelecer as bases e condições para a delegaçăo, porque a Emenda n. ${ }^{\circ} 1$ deixou a delegação ao seu exclusivo juizo.

A delegação mencionada no Decreto-lei $n .{ }^{\circ} 200$ é de competência, 0 que, a meu ver, não impede a delegação para despachar 0 . expediente, sem transferência de competência.

Mera providência administrativa, essas medidas só servem para aliviar a sobrecarga material de trabalho de chefes e certos funcionários.

Mas a delegação com transferência de competência é de conseqüências jurídicas mais graves, como já vimos.

Vamos concluir relembrando que o nosso maior objetivo fol destacar alguns aspectos mais importantes relacionados com o poder executivo no Estado moderno, ou melhor, do poder executivo em face da Constituição de 1967 e da Emenda n..$^{1}$, de 1969.

Verificamos que inovaçōes foram trazidas ao texto de 1946, que representa um tipo de Constituiçăo do imediato pós-guerra.

Essas inovações foram determinadas não somente pela necessidade de uma modernização de conceitos, como para assegurar ao poder executivo, por meio de algumas poucas providênclas, uma eficácia de ação, muitas vezes toIhida por obstáculos constitucionais que, na realidade, não constituíram exigências necessárias para assegurar a autenticidade de qualquer regime político. 
A eliminação desses obstáculos não atingiu a essência das instituições.

Elas se ajustaram a formas novas, mais modernas, sugeridas pela experiência.

Quando me refiro a formas novas não me lembro de exigências transitórias impostas por uma conjuntura intimamente ligada à segurança interna, à estabilidade das instituições, o que vale dizer, ao desenvolvimento.

A experiência universal mostra que a consolidação das infra-estruturas traz consigo maior segurança e estabilidade.

Para terminar desejo fazer uma reflexão sobre a permanência das Constituições, para afastar uma mística que nãa tenho e que não se concilia com uma concepção dinâmica do direito.

A existência de uma ordem institucional é necessária para a vida de qualquer Nação. O Brasil é um exemplo. Institucionalizou todas as suas revoluções. Constitucionalizou todos os seus regimes.

Marcou com um novo texto cada nova etapa da sua vida politica. Obedeceu a um processo de sucessiva modernização constitucional.

A Constituiçăo de 1934 integrou em nosso sistema político a mensagem de 1930 - justiça eleitoral - ordem econômica - ordem social - justiça do trabalho.

A de 1967 e 1969 reformulou o esquema da Federação, o Sistema Tributário, definiu melhor a posição dos
Estados na Federação, incluiu numerosos dispositivos motivados pelo processo de desenvolvimento econômico, disciplinou as relações executivo legislativo - deu ao executivo melhores condições para exercer a sua missão, modernizou o judiciário.

Seguiu o exemplo da França exemplo da mutabilidade constitucional, acompanhando as transformações dos regimes políticos, desde a Revolução Francesa, com todas as suas Constituiçöes (1793; ano IV, ano VIII, ano XII, seguindo-se a Carta de 1814, a Carta de 1830, a Constituição de 1840, a Constituição de 1875 , a Constituiçãu de 1946 e a de 1958).

Cada Constituição é a imagem de um momento de sua vida política constitucional.

A mistica da imutabilidade das Constituições só. deve prevalecer nos palses em que o tipo de Constituição permite reformas politicas, sociais e econômicas, que não atingem o seu texto porque disciplinam apenas as linhas gerais da estrutura politica.

0 mesmo não pode ocorrer em relação àquelas mais analiticas.

É inquestionável que as reformas e as mudanças que se estão verificando na sociedade contemporânea, o progresso tecnológico, os métodos de Governo, as exigências de enfrentar novos e graves problemas, estão a exigir pelo menos uma revisão na técnica constitucional,. nas instituiçőes fundamentais do Estado, com o objetivo de revê-las e modernizá-las, dentro de 
novos conceitos inspirados na experiência, com 0 abandono de práticas superadas.

A mistica da Constituição consiste apenas em cumprir com rigor aquela Constituição que estiver vigente.

É este o compromisso que deve ser sagrado, para que haja ordem e autoridade, fundada em um governo legitimo.

A Constituição não constitui, por si só, condição para a felicidade ou prosperidade de um povo. $O$ essencial é - comportamento justo dos responsáveis pela vida do país, Governo e oposição.

De nada adiantarn boas leis se os costumes são corruptos ou se falta competência ao Governo.

Por outro lado, não há Governo possivel sem instrumentos jurídicos adequados e que correspondam às necessídades de cada povo em um momento dado.

Os anglo-saxões afeitos a um sistema jurídico costumeiro podem pres- cindir de um regime legislativo ou constitucional mais rigido, não porém, os povos educados sob a influência do direito escrito e de normas constitucionais que detalham a estrutura do Estado e do Poder, as suas relações, o funcionamento de suas instituições e o seu sistema de garantias.

Eis porque compreendo que cada Revolução queira impor o seu ordenamento Jurídico constitucional e que todo Estado deve procurar modernizar as suas instituiçōes políticas, atualizando-as, de acordo com o progresso econômico, social e tecnológico. É conhecida a frase do abade Syées - A revolução é o poder constituinte.

O importante, segundo nos parece, para a renovação da estrutura dos poderes, deve partir de uma reformulação do tipo de relações entre eles. Para isso é necessária a revisão das condições em que cada poder é exercido, e disciplinar as relações entre eles, de forma a assegurar a autonomia de cada um, o perfeito relacionamento entre eles e a inteira eficácia de suas funções.

Como fazê-lo? É outro problema. 